\title{
Peritoneal Dialysis and In-Centre Haemodialysis: A Cost-Utility Analysis from a UK Payer Perspective
}

\author{
Catrin Treharne $\cdot$ Frank Xiaoqing Liu $\cdot$ \\ Murat Arici $\cdot$ Lydia Crowe $\cdot$ Usman Farooqui
}

Published online: 14 July 2014

(c) The Author(s) 2014. This article is published with open access at Springerlink.com

\begin{abstract}
Background With limited healthcare resources available, cost-effective provision of dialysis to patients with endstage renal disease (ESRD) is important.

Objectives To assess the cost-effectiveness of varying levels of peritoneal dialysis (PD) use versus current practice among incident ESRD patients requiring dialysis.

Methods A Markov model was developed to investigate the cost-effectiveness of increasing uptake of PD to 39 and $50 \%$ versus current practice of $22 \%$ PD from a UK National Health Service perspective for the year of 2013-2014. A scenario with $5 \%$ PD was also considered. Sensitivity analyses were performed.

Results Five- and 10-year discounted total costs and quality-adjusted life years (QALYs) per patient for the current scenario (22\% PD) were $£ 96,307$ and 2.104 , and $£ 133,339$ and 3.301, respectively. Use of PD in $39 \%$ of patients
\end{abstract}

Declarations There are no related papers published or submitted for publications associated with the aforementioned manuscript. Preliminary findings have however been communicated as a poster presentation at the American Society of Nephrology Kidney Week in November 2012.

Electronic supplementary material The online version of this article (doi:10.1007/s40258-014-0108-7) contains supplementary material, which is available to authorized users.

C. Treharne $\cdot$ L. Crowe

Abacus International, Oxfordshire, UK

F. X. Liu ( $\square)$

Baxter Healthcare Corporation, One Baxter Parkway, Deerfield,

IL 60015, USA

e-mail: Xiaoqing_liu@baxter.com

M. Arici · U. Farooqui

Baxter Healthcare Ltd, Compton, UK resulted in 5- and 10-year total per-patient cost savings of $£ 3,180$ and $£ 4,102$ versus current usage alongside total perpatient QALY increases of 0.017 and 0.020 . Use of PD in $50 \%$ of patients resulted in 5- and 10-year per-patient cost savings of $£ 5,238$ and $£ 6,758$ versus current usage alongside per-patient QALY increases of 0.029 and 0.033 . Thus, increasing use of PD was associated with marginally better outcomes and lower costs. Cost savings were driven by lower treatment costs and reduced transport requirements for PD versus haemodialysis. Reducing PD use was associated with higher costs and a small reduction in QALYs.

Conclusions These findings suggest increasing PD use among incident dialysis patients would be cost-effective, associated with reduced costs and potential modest improvements in quality of life.

\section{Key Points for Decision Makers}

Increasing peritoneal dialysis (PD) usage among incident patients with end-stage renal disease (ESRD) requiring dialysis has the potential to result in significant cost savings.

The possible clinical benefits and improvements in patient quality of life associated with PD could also reduce the burden of disease to the patient.

Implementing the use of PD as a first choice dialysis modality among appropriate patients could be a positive step towards supporting the National Health Service (NHS) QIPP (Quality, Innovation, Productivity and Prevention) programme in its aims to reduce costs while improving the quality and delivery of patient care. 


\section{Introduction}

People with end-stage renal disease (ESRD) require renal replacement therapy (RRT) in the form of dialysis or kidney transplant to sustain life. Due to ageing populations and increased risk factors such as diabetes mellitus and hypertension [1], the global prevalence of ESRD has been increasing and thus is a significant public health concern. In the European Union, the annual dialysis population growth rate in 2012 was approximately $2 \%$ [2]. In the UK, approximately 55,000 adult patients received RRT in 2012 [3] with 6,891 commencing RRT [4]. The RRT population represents approximately $2 \%$ of the total chronic kidney disease (CKD) population [5], but accounts for half of the estimated $£ 1.45$ billion spent by the English National Health Service (NHS) in 2009-2010 for care of CKD (approximately $1.3 \%$ of total NHS spending for that year) [5].

The two main types of dialysis modality are haemodialysis (HD) and peritoneal dialysis (PD). PD is homebased, administered either by a cycler whilst asleep [automated PD (APD)] or manually [continuous ambulatory PD (CAPD)]. HD is usually administered in a hospital or satellite unit, three times per week, and sometimes at home. As a home-based therapy, PD is associated with fewer travel requirements, less exposure to hospital pathogens and improved patient control. Factors determining choice of modality include availability of options, clinical contraindications and, importantly, patient preference [6]. Although evidence suggests that $50 \%$ of patients would choose PD where possible [7], the use of PD in the UK has been decreasing over the last decade $[8,9]$. In 2012 in the UK, approximately $22 \%$ of incident dialysis patients and $14 \%$ of prevalent dialysis patients used PD $[3,4]$.

The National Institute for Health and Care Excellence (NICE) guidance for England and Wales, which is produced to support people in making informed decisions about RRT, recommends that PD should be considered as the first choice of dialysis modality in adult patients without significant associated comorbidities [6]. The guidance advises that offering PD where suitable gives patients more choice and flexibility and can lead to shortterm survival benefit and improved preservation of residual renal function [10]. Currently, the UK NHS is undergoing an extensive overhaul; an integral part of this reform is the QIPP (Quality, Innovation, Productivity and Prevention) programme, which aims to improve quality and delivery of NHS care while reducing costs and achieve $£ 20$ billion of efficiency savings by 2015 [11]. A national costing report on the prevalent dialysis population published by NICE in 2011 suggests that annual savings of approximately $£ 20$ million could be made nationally if $39 \%$ of dialysis patients were to receive PD [12]. It is believed that exploring which dialysis modality or modalities should be chosen to achieve best outcomes for incident ESRD patients is valuable.

This study aimed to determine the cost-effectiveness of varying levels of PD use versus current practice among incident dialysis patients to build on a similar analysis conducted by NICE among prevalent dialysis patients [10]. The 5- and 10-year cost-effectiveness, in terms of cost per quality-adjusted life-year (QALY), of increasing the proportion of incident patients on PD to 39 and $50 \%$, or of assuming only $5 \%$ use of PD, compared with typical UK current practice $[22 \% \mathrm{PD}, 78 \%$ in-centre HD (ICHD) conventional] was investigated from the UK payer perspective.

\section{Methods}

A Markov model was developed to assess the relative costeffectiveness of different dialysis modality distribution scenarios versus current practice. The model considers a hypothetical adult incident patient cohort with ESRD requiring dialysis and adopts a UK payer perspective. Costs and benefits are discounted at a rate of $3.5 \%$ per annum in line with current UK Treasury guidance [13]. Total costs and QALYs per-patient and incremental cost-effectiveness ratios (ICERs) (expressed as cost per incremental QALY) over 5- and 10-year time horizons are estimated. Sensitivity analyses were conducted to test the robustness of our model conclusions.

\subsection{Patient Distribution and Comparators}

Default data for the reference scenario's modality distribution (22\% PD, $78 \%$ ICHD conventional), representing UK current practice, were sourced from the UK Renal Registry 16th Annual Report [4]. The UK Renal Registry, which automatically collects data quarterly from UK renal unit databases, was selected as an independent source of data and analysis. The baseline distribution of PD is: $50 \%$ CAPD and $50 \%$ APD [3]. This breakdown is assumed to be consistent in all scenarios. Alternative scenarios to UK current practice included: Scenario 1, $39 \%$ PD and $61 \%$ ICHD conventional (39\% PD was used in the recent economic evaluation by NICE [10]); Scenario 2, $50 \%$ PD, $50 \%$ ICHD conventional (evidence suggests $50 \%$ of patients would choose PD where possible [7] and some UK centres achieve this level of PD use [4]); Scenario 3, $5 \%$ PD and $95 \%$ ICHD conventional (chosen to see the effect of limited use of PD as seen in some UK centres [4]). 


\subsection{Model Structure}

The Markov model was developed in Microsoft Excel ${ }^{\circledR}$ 2010. Markov models are particularly suited to modelling chronic conditions such as ESRD [14]. The model comprises a number of discrete health states, between which patients can transition. These states include PD, ICHD, home HD (HHD) and transplant (Fig. 1). The total time horizon of the model is divided into 'cycles' of time between which patient transitions can occur. To ensure consistency in calculations, the model adopts 28-day cycles. Short model cycles, which have been used in previous, similar economic evaluations, are favoured since they increase the model's sensitivity to likely changes in health states $[15,16]$. In the model, from one cycle to the next, the patient may stay on their current modality, switch to a different modality, have a kidney transplant or die. Whilst on dialysis, patients face a probability of complications that is dependent only on their current dialysis modality. Patients can die in any state and only one movement is allowed per cycle. Once a patient dies, they no longer accrue costs and QALYs.

\subsection{Model Inputs}

\subsubsection{Clinical Data}

Relevant clinical data were identified in previous economic evaluations and NICE publications. Systematic reviews that had been previously conducted to populate a number of similar models were identified, and an additional rapid literature review was performed to identify studies and data published in the interim. Where more than one relevant data source was identified, to be conservative, the one that generated a higher incremental cost effectiveness ratio (ICER) was used. The clinical input data and sources of the data are shown in Table 1 and are described in more detail below.

\subsubsection{Survival}

Survival was estimated based on data from the ERA-EDTA Annual Report 2009 [17], which relates to European incident patients on dialysis, and was used because the UK Renal Registry reports do not provide such detailed information on patient survival. The age and gender distribution of patients in the UK was found to be comparable to those in patients in the US and in other European countries based on data published by the USRDS (US) [18] and ERAEDTA (Europe) [19] registries. It was therefore deemed appropriate to use European ERA-EDTA registry data to approximate the UK population in this analysis. The survival curves published in the ERA-EDTA report permit parametric modelling of survival, whereas the UK Renal Registry's summary statistics do not. Five-year survival curves for HD and PD patients were digitised and the data obtained converted into a patient-level data set and analysed in the statistical package, R [20]. Further information regarding the $\mathrm{R}$ survreg function is provided as Electronic Supplementary Material accompanying this article. In order to extrapolate PD and HD survival beyond 5 years, parametric survival models were fitted to the data. Since extrapolating the available 5-year HD and PD data beyond 10 years would cause more uncertainty and as a result be less reliable, it was assumed that there were no differences in mortality rates between modalities after 10 years. This is in line with the review paper by Chiu [21], which reported that 'virtually all the recent observational studies from different parts of the world consistently show that longterm survival of HD and PD patients is remarkably similar'. Average extrapolated mortality rates were used across all dialysis modalities beyond 10 years. Survival of patients post-transplant was modelled using 5-year summary survival data for the 2005-2007 transplant cohort from NHS blood and transplant's activity report for 2012/2013 [22].

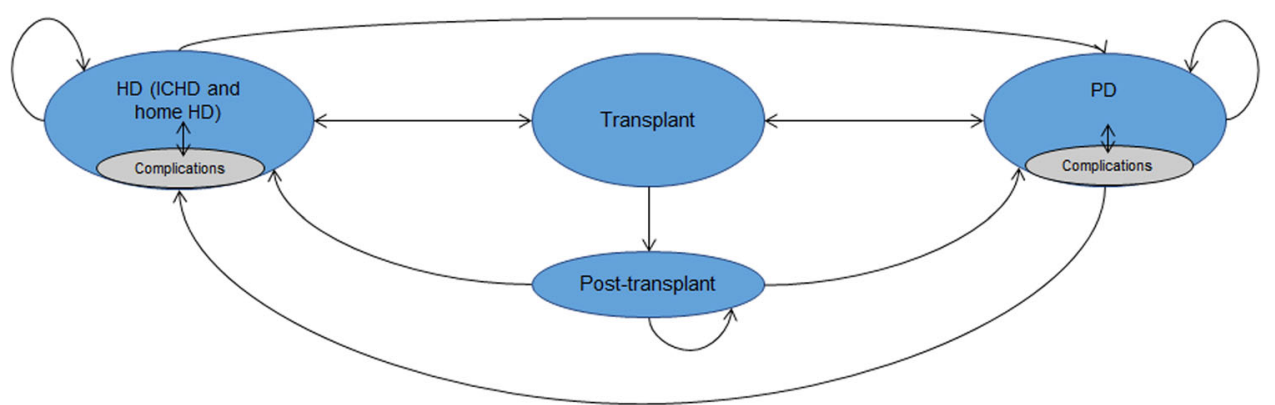

Fig. 1 Model flow diagram. One-way arrows indicate that patients can move in one direction; two-way arrows indicate that patients can move in either direction. Each dialysis modality is a separate health state in the model, as follows: in-centre haemodialysis (ICHD) conventional $=$ hospital or satellite; home haemodialysis (HHD) conventional; $\mathrm{PD}=$ continuous ambulatory peritoneal dialysis (CAPD) or automated peritoneal dialysis (APD); transplant (transient health state); post-transplant. Patients can die from any of the model's health states. The absorbing death state is not shown in this diagram 
Table 1 Clinical input data

\begin{tabular}{lccc}
\hline Clinical parameter & Value (range $)^{\dagger}$ & $\begin{array}{c}\text { Parameter } \\
\text { distribution }\end{array}$ & Data sources \\
\hline HD exponential model intercept & $1.98(1.49-2.48)$ & $\begin{array}{l}\text { Lognormal } \\
\text { Lognormal }\end{array}$ & ERA-EDTA survival data \\
PD Weibull model intercept & $1.92(1.44-2.40)$ & Lognormal & \\
PD Weibull scale & $0.82(0.62-1.03)$ & Lognormal & \\
Hazard ratio to reflect an incident cohort & $1.06(0.80-1.33)$ & Beta & Liem [28] \\
Adjusting life to its quality: baseline utility values for patients in all health states & deWit, Liem [28, 29] \\
ICHD conventional (hospital and satellite) & $0.56(0.49-0.62)$ & Beta & Liem [28] \\
HHD conventional & $0.69(0.52-0.86)$ & Beta & Liem [28]
\end{tabular}

Dialysis modality switching assumptions: 28-day probability of switching modalities (incident population): $\%$

$\begin{array}{ll}\text { HD to PD } & \\ 0-6 \text { months } & 3.58(2.69-4.48) \\ 7-12 \text { months } & 0.08(0.06-0.10) \\ 13-18 \text { months } & 0.08(0.06-0.10) \\ \text { 19+ months } & 0.08(0.06-0.10) \\ \text { PD to HD } & \\ 0-6 \text { months } & 2.61(1.96-3.26) \\ 7-12 \text { months } & 1.13(0.85-1.41) \\ 13-18 \text { months } & 0.78(0.58-0.97) \\ 19+\text { months } & 0.31(0.23-0.39) \\ \text { ICHD to HHD } & \\ 0-6 \text { months } & 0.05(0.04-0.06) \\ 7-12 \text { months } & 0.05(0.04-0.06) \\ 13-18 \text { months } & 0.03(0.02-0.04) \\ 19+\text { months } & 0 \\ \text { HHD to ICHD } & \\ 0-6 \text { months } & 0.38(0.29-0.48) \\ 7-12 \text { months } & 0.38(0.29-0.48) \\ 13-18 \text { months } & 0.38(0.29-0.48) \\ 19+\text { months } & 0.38(0.29-0.48) \\ \end{array}$

Dialysis complications: 28-day probability of all-cause hospitalisation: $\%$

ICHD conventional (hospital and satellite)

Year one

Subsequent years

HHD conventional

Year one

Subsequent years

All PD modalities

Year one and subsequent years

Breakdown of transplant type by donor: \%

Living

$7.05(5.29-8.81)$

$4.86(3.65-6.08)$

$5.35(4.01-6.68)$

$3.68(2.77-4.61)$

$7.05(5.29-8.81)$

$36(27.0-45.0)$

$39(29.3-48.8)$

$25(18.8-31.3)$

Annual transplant probability: \%

All patients
$9(7-11)$
Beta

Johnson [54]

Beta

Baxter UK hospital data

Beta

Assumption

Beta

McFarlane [55]

Beta

FHN trial [31]

Based on Arora [32]

Beta

Rocco [56]

Based on Arora [32]

Beta

Based on Lafrance ${ }^{\dagger \dagger}[30,31]$

Dirichlet

NHS Blood and Transplant Activity Report 2012/2013 [22]

Beta

UK Renal Registry report data [57, 58] 
Table 1 continued

\begin{tabular}{|c|c|c|c|}
\hline Clinical parameter & Value (range) $)^{\dagger}$ & $\begin{array}{l}\text { Parameter } \\
\text { distribution }\end{array}$ & Data sources \\
\hline \multicolumn{4}{|c|}{ Annual graft failure probability by donor type } \\
\hline Living & $0.03(0.03-0.04)$ & Beta & \multirow{4}{*}{$\begin{array}{l}\text { NHS Blood and Transplant Activity } \\
\text { Report 2012/2013 [22] }\end{array}$} \\
\hline Donor after brain death & $0.06(0.06-0.07)$ & & \\
\hline Donor after cardiac death & $0.08(0.07-0.10)$ & & \\
\hline Weighted average & 0.05 & & \\
\hline \multicolumn{4}{|c|}{ Annual access failure probability: $\%$} \\
\hline HD vascular access & $10(7.5-12.5)$ & Beta & Xue [33] \\
\hline \multicolumn{4}{|c|}{$E S R D$ end-stage renal disease, $H H D$ home haemodialysis, $I C H D$ in-centre haemodialysis, $P D$ peritoneal dialysis } \\
\hline \multicolumn{4}{|c|}{$\begin{array}{l}\text { Variables were varied according to published ranges or by } \pm 25 \% \text { for those variables without such information. Published confidence intervals } \\
\text { were available for the transplant graft failure rates [59], certain switching rate inputs [45] and the quality of life values [28] }\end{array}$} \\
\hline \multicolumn{4}{|c|}{$\begin{array}{l}\text { The distributions selected are widely believed to be appropriate choices for the model parameters and reflect best practice. The beta distribution } \\
\text { is a suitable choice for probability parameters (percentages or proportions) since it is defined on the interval }[0,1] \text {. The Dirichlet distribution, } \\
\text { used for the breakdown of transplants by donor type, is an extension of the beta distribution, which can be used in the case of several mutually } \\
\text { exclusive categories. The lognormal distribution was selected for survival parameters since it constrains parameters to positive values }\end{array}$} \\
\hline \multicolumn{4}{|c|}{$\begin{array}{l}\S \text { Survival parameters correspond to distributions embedded in a general location-scale family. For more information, please see the } \mathrm{R} \text { survreg } \\
\text { function support pages provided as additional electronic supplementary material }\end{array}$} \\
\hline \multicolumn{4}{|c|}{$\begin{array}{l}\text { Ratio of limited care HD to conventional HD utility scores from deWit [29] is applied to the HD value from Liem [28] [0.56 } \times(0.81 / \\
0.66)=0.69]\end{array}$} \\
\hline
\end{tabular}

\subsubsection{Quality-of-Life}

Dialysis modality has the potential to impact upon patients' quality-of-life (QoL). It has been reported that PD patients have less illness intrusion, better renal care and higher satisfaction, while HD patients have better staff and social interaction and less fear of isolation [23-27]. The model includes the utility of patients that varied between different dialysis modalities and between patients on dialysis and those receiving a kidney transplant. A systematic review and meta-analysis conducted by Liem [28] was used as the main source of utility values for the model; this was also used in NICE clinical guideline (CG) 125 . The utility value assigned to patients receiving HHD was based on the combined approach of NICE CG 125 [6] and NHS CEP10063 [16]. The utility value assigned to ICHD conventional from the Liem study [28] was multiplied by a ratio of limited care HD to HD conventional utility scores taken from the study by de Wit [29] to estimate a utility value for conventional HHD.

\subsubsection{Transition Probabilities}

Patients may change dialysis modalities because of complications and changes in preference or living conditions. Estimated transition probabilities for the model are shown in Table 1. When patients change dialysis modality they are redistributed according to the baseline distribution of the modality to which they change. For example, if a patient moves from HD to PD, whether they move to APD or CAPD is dependent on how PD patients are distributed between these modalities at baseline $(\mathrm{CAPD}=50 \%$; APD $=50 \%$ ). The probability of a patient staying in the same modality from one cycle to the next is taken to be equal to 1 minus the probability that they move. Following a transplant, all patients move to the post-transplant state where they stay until graft failure/death. If graft failure occurs, the patient's subsequent dialysis setting is dependent on the scenario's baseline patient distribution.

\subsubsection{Dialysis Complications}

Patients undergoing dialysis may experience complications. The model looks specifically at all-cause hospitalisations as an encompassing approach. Since no studies reporting all-cause hospitalisation probabilities in patients on PD in the UK were available, to be conservative, it was assumed that the rate was the same as for HD [30, 31] (Table 1). All-cause hospitalisation probabilities in subsequent years were calculated by applying a ratio of firstyear to subsequent-year hospitalisation rates derived from the study by Arora [32]. In HD patients, hospitalisation rates in subsequent years are $30 \%$ lower than in the first year, whereas for PD patients hospitalisations occur at the same rate in subsequent years as in the first year.

\subsubsection{Cost Data}

In line with the UK National Health Spending perspective, the model included the following important cost 
components: access establishment and maintenance [33, 34], provision of dialysis services [34], erythropoiesis-stimulating agents (ESA) [35, 36], patient monitoring [34], all-cause hospitalisation [34, 37], transportation to and from dialysis clinics [38-40] and kidney transplantation costs $[41,42]$. It is assumed that these elements capture the principal costs associated with the treatment of ESRD patients. Detailed cost input data (year of valuation 2013-2014) are shown in Table 2.

\subsection{Cost-Effectiveness Analysis}

For the base case analysis, three alternative scenarios with 39, 50 and $5 \%$ PD respectively were compared with the current clinical practice of $22 \%$. In line with current UK Treasury guidance, future costs and benefits were discounted at an annual rate of $3.5 \%$ [13]. The main outcome measure was the ICER, the cost per incremental QALY. Given the available survival data and in line with previous economic evaluations in ESRD [6, 43, 44], 5- and 10-year time horizons were presented as main results.

\subsection{Sensitivity Analyses}

One-way sensitivity analyses were performed to assess how sensitive results were to changes in model parameters. All model parameters were individually varied between a minimum and maximum value and their impact on model results recorded. Variables were altered according to published ranges (available for transplant graft failure rates [22], certain switching rate inputs [45] and utility values [28]) or by $\pm 25 \%$ for those variables without such information. The following parameters were analysed: allcause hospitalisation rates, transition probabilities, survival parameters, costs, transplant and graft failure rates, and utilities. Parameter ranges are shown in Tables 1, 2. Results are presented in the form of a tornado diagram.

Probabilistic sensitivity analysis (PSA) was also conducted. In PSA, model parameters are assigned appropriate statistical distributions and are permitted to vary according to those distributions. Running a large number of simulations allows a more accurate assessment of the effect of parameter uncertainty on model results. Distributions assigned to parameters in the PSA are shown in Tables 1 and 2. PSA results are presented in the form of a costeffectiveness plane scatter diagram and a cost-effectiveness acceptability curve (CEAC).

Further sensitivity analyses for different time horizons beyond 10 years, including 15, 20, 30 and 40 years, were also conducted to test the robustness of the model conclusions.

\section{Results}

Table 3 presents the results for the cost-effectiveness model with regard to total costs, QALYs and the ICER. For the reference scenario, total discounted costs and QALYs per patient over 5- and 10-year time horizons were $£ 96,307$ and 2.104 and $£ 133,339$ and 3.301, respectively. Assuming an increase in PD to $39 \%$ of all dialysis use in incident dialysis patients (Scenario 1), the cost difference versus the reference scenario was a saving of $£ 3,180$ over 5 years and $£ 4,102$ over 10 years per patient, with a small increase in QALYs of 0.017 over 5 years and 0.020 over 10 years per patient. Scenario 1 was dominant, providing better outcomes at lower costs. When assuming an increase in PD to $50 \%$ of all dialysis use in incident dialysis patients (Scenario 2), the cost difference versus the reference scenario was a saving of $£ 5,238$ over 5 years and $£ 6,758$ over 10 years per patient. In this case, the difference in QALYs was a small increase of 0.029 over 5 years and 0.033 over 10 years per patient; hence Scenario 2 was also dominant. If the use of PD in incident dialysis patients decreases to $5 \%$ (Scenario 3), the cost difference versus the reference scenario was an increase of $£ 3,179$ over 5 years and $£ 4,098$ over 10 years per patient. The difference in QALYs was a small decrease of 0.017 over 5 years and 0.020 over 10 years per patient; in this case, Scenario 3 was dominated (associated with worse outcomes and higher costs). Results over longer time horizons of 15-40 years were consistent with the 10 year results.

\subsection{Sensitivity Analyses}

As the costing report associated with NICE CG125 cites $39 \%$ PD as the optimal level [12], sensitivity analysis results are only reported for Scenario 1 (39 \% PD) versus the reference scenario. Figure 2 shows the results of the one-way sensitivity analysis for scenario 1 at 10 years. As can be seen from the $\mathrm{x}$-axis, the net benefit never falls below zero, indicating that Scenario 1 remained costeffective relative to the reference scenario over the range of variables tested [46]. The net benefit calculation assigns a monetary value to the incremental health gains (QALYs) achieved. The incremental cost of achieving these gains is subtracted from their monetary value to give the net benefit. If the resulting figure is positive, this indicates that the monetary value of the health gains exceeds the incremental cost and the intervention is considered to be cost-effective. Likewise, if the net benefit is negative then the intervention is not considered to be cost-effective. To be conservative, the willingness-to-pay value used for the calculation of the net benefit was $£ 20,000$. The model is mostly sensitive to costs and survival parameters-changes in the values of 
Table 2 Cost input data

\begin{tabular}{|c|c|c|}
\hline Parameter & Value (range) ${ }^{\dagger}$ & Data sources \\
\hline \multicolumn{3}{|l|}{ HD-related costs } \\
\hline Vascular access cost & $£ 1,287(£ 965-£ 1,609)$ & PbR tariff 2013-2014 [34] \\
\hline \multicolumn{3}{|l|}{ ICHD cost per session } \\
\hline Catheter access & $£ 121(£ 92-£ 154)$ & PbR tariff 2013-2014 [34] \\
\hline AV fistula/graft access & $£ 152(£ 115-£ 191)$ & \\
\hline Weighted & $£ 147$ & $\begin{array}{l}\text { Breakdown based on the target percentage set by the best practice } \\
\text { tariff for } 2013-2014[60]\end{array}$ \\
\hline Home HD cost per week & $£ 456(£ 342-£ 570)$ & $\mathrm{PbR}$ tariff 2013-2014 [34] \\
\hline \multicolumn{3}{|l|}{ HD conventional ESA cost } \\
\hline Dose (units/week) & $6,306(4,730-7,883)$ & Rao [61] \\
\hline ESA cost per 1,000 units & $£ 5.09(£ 3.82-£ 6.36)$ & BNF No. 67 [35] \\
\hline Cost per HD hospitalisation & $£ 1,887(£ 1,415-£ 2,359)$ & $\begin{array}{l}\text { Event costs from the PbR tariff 2013-2014 [34]. Event numbers from } \\
\text { the National Schedule of Reference Costs 2011-2012 [37] }\end{array}$ \\
\hline \multicolumn{3}{|l|}{ PD-related costs } \\
\hline Peritoneal access costs (PD specific) & $£ 1,233(£ 854-£ 1,423)$ & $\mathrm{PbR}$ tariff 2013-2014 [34] \\
\hline \multicolumn{3}{|l|}{ PD cost per day } \\
\hline APD & $£ 52(£ 39-£ 65)$ & PbR tariff 2013-2014 [34] \\
\hline CAPD & $£ 46(£ 35-£ 58)$ & \\
\hline \multicolumn{3}{|l|}{ PD ESA cost (all sub-modalities) } \\
\hline Dose (units/week) & $2,933(2,200-3,666)$ & Rao [61] \\
\hline ESA cost per 1,000 units & $£ 5.09(£ 3.82-£ 6.36)$ & BNF No. 67 [35] \\
\hline Cost per PD hospitalisation & $£ 1,504(£ 1,128-£ 1,880)$ & $\begin{array}{l}\text { Event costs from the PbR tariff 2013-2014 [34]. Event numbers from } \\
\text { the National Schedule of Reference Costs 2011-2012 [37] }\end{array}$ \\
\hline \multicolumn{3}{|l|}{ Overall (common) costs } \\
\hline \multicolumn{3}{|l|}{ Transplant cost } \\
\hline Donor after brain death & $£ 19,804(£ 14,853-£ 24,755)$ & National Schedule of Reference Costs 2012-2013 [42] \\
\hline Donor after cardiac death & $£ 16,580(£ 12,435-£ 20,725)$ & \\
\hline Living donor & $£ 18,640(£ 13,980-£ 23,300)$ & \\
\hline Weighted & $£ 18,579$ & $\begin{array}{l}\text { Breakdown based on the NHS Blood and Transplant Activity Report } \\
\text { for 2012-2013 [59] }\end{array}$ \\
\hline Post-transplant medication costs & $£ 11,137(£ 8,352-£ 13,921)$ & NHS Kidney Care report [41] \\
\hline \multicolumn{3}{|l|}{ Monitoring costs } \\
\hline Single professional & $£ 132(£ 99-£ 165)$ & $\mathrm{PbR}$ tariff 2013-2014 [34] \\
\hline Multi professional & $£ 247(£ 185-£ 309)$ & \\
\hline Weighted & $£ 190$ & Equal weighting assumed \\
\hline \multirow[t]{4}{*}{ Transport cost per visit } & $£ 44(£ 33-£ 55)^{\S}$ & NHS Law on tariffs [38] \\
\hline & & National Schedule of Reference Costs 2009-2010 [39] \\
\hline & & National Schedule of Reference Costs 2010-2011 [62] \\
\hline & & National Kidney Care Audit, Patient Transport Survey 2010 [40] \\
\hline
\end{tabular}

$A P D$ automated peritoneal dialysis, $A V$ arteriovenous, $C A P D$ continuous ambulatory peritoneal dialysis, $E S A$ erythropoiesis-stimulating agents, $H D$ haemodialysis, $I C H D$ in-centre haemodialysis, $P b R$ payment by results, $P D$ peritoneal dialysis

${ }^{\dagger}$ All cost parameters are assigned gamma distributions for PSA; this reflects best practice. The gamma distribution is constrained to nonnegative values and can be used to represent uncertainty in cost parameters

* Patients on each modality are assumed to receive two monitoring visits/year

$\S$ The weighted average cost of hospital-arranged transport was estimated to be $£ 69$. However, it is estimated that $36 \%$ of transport visits are paid for by the patient; therefore, the overall weighted average cost per transport visit reflects this 
Table 3 Results of the effect of varying the proportion of incident patients on PD showing the total costs, QALYs per patient and the ICER

\begin{tabular}{|c|c|c|c|}
\hline & Total costs $(\mathfrak{f})$ & QALYs & ICER (vs. reference scenario) \\
\hline Reference scenario ( 5 years) & 96,307 & 2.104 & - \\
\hline Scenario 1 (39 \% PD) & 93,127 & 2.121 & Dominant* \\
\hline Scenario 2 (50 \% PD) & 91,069 & 2.133 & Dominant* \\
\hline Scenario 3 (5 \% PD) & 99,486 & 2.087 & Dominated $^{* *}$ \\
\hline Reference scenario (10 years) & 133,339 & 3.301 & - \\
\hline Scenario 1 (39 \% PD) & 129,237 & 3.321 & Dominant* \\
\hline Scenario 2 (50 \% PD) & 126,580 & 3.334 & Dominant* \\
\hline Scenario 3 (5 \% PD) & 137,436 & 3.281 & Dominated $* *$ \\
\hline \multicolumn{4}{|c|}{ For the following time horizons, equal survival was assumed after 10 years } \\
\hline Reference scenario (15 years) & 151,531 & 4.035 & - \\
\hline Scenario 1 (39 \% PD) & 146,982 & 4.054 & Dominant* \\
\hline Scenario $2(50 \%$ PD) & 144,035 & 4.067 & Dominant* \\
\hline Scenario 3 (5 \% PD) & 156,074 & 4.016 & Dominated $^{* *}$ \\
\hline Reference scenario (20 years) & 161,864 & 4.499 & - \\
\hline Scenario 1 (39 \% PD) & 157,088 & 4.518 & Dominant* \\
\hline Scenario $2(50 \%$ PD) & 153,993 & 4.530 & Dominant* \\
\hline Scenario 3 (5 \% PD) & 166,635 & 4.479 & Dominated $* *$ \\
\hline Reference scenario (30 years) & 172,255 & 4.987 & - \\
\hline Scenario 1 (39 \% PD) & 167,256 & 5.006 & Dominant* \\
\hline Scenario $2(50 \%$ PD) & 164,018 & 5.019 & Dominant* \\
\hline Scenario 3 (5 \% PD) & 177,248 & 4.968 & Dominated $* *$ \\
\hline Reference scenario (40 years) & 176,465 & 5.189 & - \\
\hline Scenario 1 (39 \% PD) & 171,378 & 5.208 & Dominant* \\
\hline Scenario $2(50 \%$ PD) & 168,082 & 5.220 & Dominant* \\
\hline Scenario 3 (5 \% PD) & 181,546 & 5.169 & Dominated** \\
\hline
\end{tabular}

ICER incremental cost effectiveness ratio, $Q A L Y$ quality-adjusted life year

* Better outcomes, lower costs

** Worse outcomes, higher costs

these parameters have the biggest impact on the overall result.

Figure 3 shows the results of the PSA for Scenario 1 (i.e. $39 \%$ of incident patients on PD). The cost-effectiveness plane represents the results of 1,000 simulations in terms of incremental costs and QALYs. Scenario 1 was less expensive than the reference scenario in $96.3 \%$ of simulations, 95th percentile interval for incremental costs $(-£ 8,585, £ 202)$. However, in $38 \%$ of simulations Scenario 1 was less costly but also less effective (i.e. it falls in the South-West quadrant), 95th percentile interval for incremental QALYs $(-0.088,0.124)$. The CEAC presents the probability that Scenario 1 was cost-effective versus the reference scenario at different values of the willingness-topay threshold (up to $£ 50,000$ ). The probability is based on the proportion of simulations in which the net benefit is positive. The results demonstrate that the probability that Scenario 1 was cost-effective at each willingness-to-pay threshold value of $0-£ 50,000$ was almost $100 \%$.

\section{Discussion}

The results of this study suggest that increasing PD use among new patients with ESRD initiating dialysis from the current $22 \%$ to either 39 or $50 \%$ would be cost-effective, associated with reduced costs and modest improvements in health outcomes. Reducing PD use to $5 \%$, however, would result in higher costs and worse outcomes. The range of QALY differences observed in the sensitivity analyses reflects the clinical uncertainty surrounding the relative effectiveness of PD and HD; thus, dominance cannot be presumed. However, the cost savings associated with increasing PD use to $39 \%$ of incident dialysis patients are such that one can be confident that it will be deemed costeffective. Results were also considered for longer time horizons of 15, 20, 30 and 40 years and were found to be consistent with the results for 10 years.

These findings are consistent with prior studies on this topic. The cost-effectiveness analysis conducted by NICE 


\section{Tornado Diagram}

HD median survival (years) 5.02 (3.06 - 8.24)

Number of sessions per week for Hospital conventional 3 (2.25 - 3.75)

PD median survival (years) 5.06 (3.13 - 8.19)

Hospital (AV Fistula/Graft) conventional reimbursement $£ 152(£ 114-£ 190)$

Number of sessions per week for Sat / low care conventional 3 (2.25 - 3.75)

APD reimbursement $£ 52(£ 39-£ 65)$

CAPD reimbursement $£ 46(£ 35-£ 58$ )

Sat / Iow care (AV Fistula/Graft) conventional reimbursement $\_152(£ 114-£ 190)$

Transportation cost (single value) $£ 44$ ( $\left.\_33-£ 55\right)$

Incident vs prevalent HR $1.06(0.795-1.325)$

Mortality HR vs 2000 cohort of patients $1(0.75-1.25)$

CAPD utility - Liem $0.58(0.5-0.67)$

APD utility - Liem $0.58(0.5-0.67)$

PD median survival (years) 5.06 (5.46 - 4.69)

Conventional ICHD Hospital utility - Lem $0.56(0.49-0.62)$

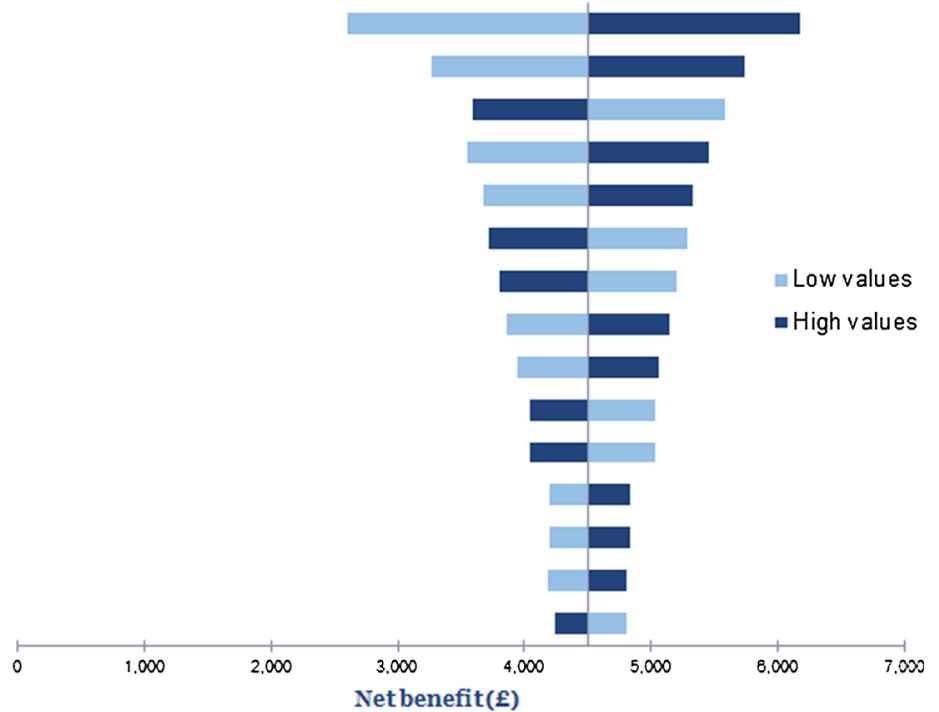

Netbenefit $(£)$
Fig. 2 One-way sensitivity analysis for Scenario 1 (PD $39 \%$; ICHD conventional $61 \%$ ): Tornado diagram for the top 15 parameters10 year results. The tornado diagram shows the sensitivity of the net benefit (NB) to changes in the model parameters. The value of each parameter in the model was replaced in turn, first with its lowest plausible value, then its highest plausible value; the resulting variation in the NB permits the identification of parameters that are key drivers of the model outcome. Parameters having the most impact



Fig. 3 Probabilistic sensitivity analysis for Scenario 1 (PD $39 \%$; ICHD conventional $61 \%$ )-10-year results. Model parameters are assigned suitable statistical distributions and are permitted to vary according to those distributions. The cost-effectiveness plane shows the results of 1,000 simulations plotted on a scatter plot of

analysed the prevalent population in order to determine whether the proportion of patients on PD should be increased in England and Wales [47]. Compared with the reference scenario (Hospital HD $47 \%$, Satellite HD $33 \%$, HHD $2 \%$, CAPD $14 \%$, APD $4 \%$ ), increasing PD use (Hospital HD $8.5 \%$, Satellite HD $49 \%$, HHD 9.5\%, CAPD $20 \%$, APD $13 \%$ ) resulted in reduced costs (reference scenario £130,234; PD scenario £120,200) and better QALYs (reference scenario 3.77; PD scenario 3.87) on the NB are shown at the top of the tornado diagram with the biggest bars and those that have the least impact are at the bottom of the diagram with the smallest bars. To be conservative, a willingnessto-pay value of $£ 20,000 / \mathrm{QALY}$ was used for the calculation of the NB. $A P D$ automated peritoneal dialysis, $A V$ arteriovenous, $C A P D$ continuous ambulatory peritoneal dialysis, $H D$ haemodialysis, $H H D$ home haemodialysis, $H R$ hazard ratio, ICHD in-centre haemodialysis, $P D$ peritoneal dialysis, $S A T$ satellite unit

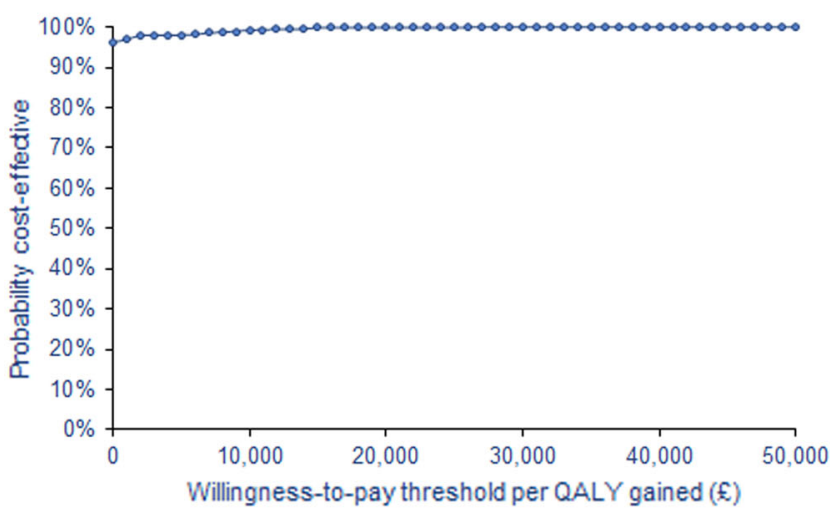

incremental costs and incremental effectiveness [quality-adjusted life years (QALY)] for Scenario 1 versus the reference scenario. The costeffectiveness acceptability curve presents the probability that Scenario 1 (39\% PD) is cost-effective versus the reference scenario at different values of the willingness-to-pay threshold

and was dominant at 10 years. It has been reported that increasing use of PD from current levels (approximately $15 \%)$ to $39 \%$ among prevalent patients is cost-effective and could realise annual savings of approximately $£ 20$ million nationally [12]. When the NICE scenario was tested as closely as possible in the current model using the prevalent population (data inputs not shown), it was found that increasing PD also resulted in reduced costs (reference scenario £138,606; PD scenario £132,969) and better 
QALYs (reference scenario 3.38; PD scenario 3.43) as well as a dominant ICER versus the reference scenario. However, the decision to focus on incident dialysis patients rather than prevalent dialysis patients is in response to the perceived benefits of starting incident patients on PD; these include improved early survival and better preservation of residual renal function [46, 48, 49].

Studies from other countries have also reported that increasing PD use in incident patients with ESRD requiring dialysis is cost-effective $[45,50,51]$. To the authors' knowledge, this is the only study that has looked at increasing the proportion of PD use among incident patients from the perspective of the UK NHS. Neil et al. used a budget impact analysis to estimate the countryspecific, 5-year financial impact on total dialysis costs, assuming utilisation shifts from HD to PD in the prevalent population in two high-income, three upper-middle-income and three lower-middle-income countries [52]. This study found that increasing PD rates could be significantly costsaving compared with HD in all the studied countries, including the UK.

The key strengths of the current analysis are first that the model structure was informed by previous economic evaluations in ESRD including the analysis conducted by NICE in relation to CG 125-peritoneal dialysis [10]. Second, model assumptions and inputs were validated at a clinical advisory board and with a UK-based nephrology key opinion leader who had been involved in both inpatient and outpatient NHS renal services and was involved in the NICE appraisals of HD and PD.

Although the best-available published evidence was used to model costs and benefits associated with increasing PD use among incident patients with ESRD requiring dialysis, the analysis has several limitations. First, some data may not be completely representative of current clinical practice in the UK, as some model inputs were derived from other countries where clinical practice might be different. Survival, for example, is based on European data in which UK patients represent $20 \%$ of all incident patient counts [17]. In order to facilitate future research and economic evaluations in the UK, it would be very valuable to have more comprehensive UK-based clinical and epidemiological data, including long-term comparative survival data for PD vs. ICHD. Second, the current data are only applicable to adult patients who are suitable and willing candidates for PD. Patient suitability is based on NICE clinical guidelines. Third, to calculate the number of hospitalisations in subsequent years versus the first year, data from a study published by Arora in 2000 were usedmore recent data were not identified [32]. This study suggested that the rate of hospitalisations in PD patients did not drop in subsequent years while in HD patients the rate dropped by $30 \%$. Since PD technology has improved significantly in the interim, the number of hospitalisations in PD patients may be overestimated. Thus, the results may be biased in favour of HD. Fourth, given the payer perspective of the analysis, indirect costs related to working days lost, direct out-of-pocket costs to patients and carers were not incorporated. Fifth, with regard to other medication costs, there is currently a lack of evidence demonstrating that these costs differ between the different treatment modalities within the UK. Finally, data availability did not permit the consideration of the relative clinical efficacy of APD versus CAPD. Therefore these conclusions relate to PD in general as conducted in the UK. This analysis does not advocate one kind of PD treatment over another.

The present study may have important implications for policymakers. As part of extensive healthcare reform in the UK, the QIPP programme aims to improve the quality and delivery of NHS care while making efficiency savings. For example, one aim is to "reduce expensive hospital admissions by: getting patients more involved in managing their own conditions; where possible treating more patients closer to home" [53]. The current results show that PD is associated with quality improvements and cost savings compared to conventional ICHD. The increased use of PD could make a significant contribution to the target of achieving $£ 20$ billion efficiency savings by 2015 while improving the quality of a patient-focussed health service.

In summary, this study suggests that using PD in line with NICE recommendations may be a cost-effective method of treating incident ESRD patients requiring dialysis. It is acknowledged also that there are some limitations associated with this analysis due to many of the model inputs being based on data not specifically relating to the UK. Additionally, the results of the PSA show that there is uncertainty regarding the clinical benefits of PD over other dialysis modalities. Further research is therefore warranted into the clinical comparative effectiveness of PD versus HD. However, this study suggests that, from a UK payer perspective, increasing the proportion of patients on $\mathrm{PD}$ could lead to cost reductions while also improving clinical outcomes and QoL, thus alleviating the burden to the patient. The results suggest that policies encouraging the use of PD as the first dialysis option would help support implementation of the NHS QIPP agenda and that quality of care could be improved with reduced resource use.

Acknowledgments The authors thank Dr Andrew Buckland (Abacus International), Dr Andrea Ditchfield (Abacus International) and Dr Amanda Prowse for assistance in writing the article.

This study was funded by Baxter Healthcare Corp. Frank Xiaoqing Liu, Murat Arici and Usman Farooqui are paid employees of Baxter Healthcare Corp/Ltd. Catrin Treharne and Lydia Crowe are employees of Abacus International, a health outcomes consultancy commissioned by Baxter to conduct the economic analysis. This 
research received no specific grant from any funding agency in the public, commercial or not-for-profit sectors.

Author contributions Catrin Treharne performed the economic model development, assisted with data collection and was involved in the manuscript development and review. Frank Xiaoqing Liu was responsible for the model structure design, contributed to data collection, reviewed and approved the economic model described in the manuscript, and was also involved in manuscript development and review. Murat Arici assisted in collection of cost data, reviewing data inputs and review of the manuscript. Lydia Crowe was involved in development of the economic model described in the manuscript and in the review of the manuscript. Usman Farooqui provided clinical data inputs and reviewed and commented the manuscript. All authors approved the final manuscript. The guarantor for the overall content of the manuscript is Frank Xiaoqing Liu.

Open Access This article is distributed under the terms of the Creative Commons Attribution Noncommercial License which permits any noncommercial use, distribution, and reproduction in any medium, provided the original author(s) and the source are credited.

\section{References}

1. Ayodele OE, Alebiosu CO. Burden of chronic kidney disease: an international perspective. Adv Chronic Kidney Dis. 2010;17(3): 215-24

2. Fresenius Medical Care. ESRD patients in 2012. A global perspective. Available from: http://www.vision-fmc.com/files/pdf_2/ ESRD_Patients_2012.pdf. Accessed Aug 2013.

3. Shaw C. UK Renal Registry 16th Annual Report: Chapter 2 UK RRT Prevalence in 2012: National and Centre-specific Analyses. 2013. Available from: http://www.renalreg.com/Report-Area/ Report\%202013/02-Chap-02.pdf. Accessed Jan 2014.

4. Gilg J. UK Renal Registry 16th Annual Report: Chapter 1 UK Renal Replacement Therapy Incidence in 2012: National and Centre-specific Analyses. 2013. Available from: http://www.renalreg. com/Report-Area/Report\%202013/01-Chap-01.pdf. Accessed Jan 2014.

5. Kerr M, Bray B, Medcalf J, O’Donoghue DJ, Matthews B. Estimating the financial cost of chronic kidney disease to the NHS in England. Nephrol Dial Transplant. 2012;27(Suppl 3):iii73-80.

6. National Institute for Health and Clinical Excellence (NICE). Peritoneal dialysis (Clinical guidelines, CG125). Peritoneal dialysis in the treatment of stage 5 chronic kidney disease. Available from http://www.nice.org.uk/nicemedia/live/13524/ 55517/55517.pdf. Accessed Apr 2013.

7. Jager KJ, Korevaar JC, Dekker FW, Krediet RT, Boeschoten EW. The effect of contraindications and patient preference on dialysis modality selection in ESRD patients in The Netherlands. Am J Kidney Dis. 2004;43(5):891-9.

8. Brady M, O'Donoghue D. Back to the future: changes in the dialysis delivery model in the UK. Perit Dial Int. 2011;31(Suppl 2):S63-72.

9. Castledine CI, Caskey FJ, Tomson CR, Ansell D. Trends in renal replacement therapy and changes in peritoneal dialysis utilization in the United kingdom. Perit Dial Int. 2011;31(Suppl 2):S53-7.

10. National Institute for Health and Clinical Excellence (NICE). Cost effectiveness of peritoneal dialysis provision. Available from: http://www.nice.org.uk/nicemedia/live/12347/52540/52540. pdf. Accessed Apr 2013.

11. National Health Service (NHS) Improvement. E-QIPP. Available from http://www.improvement.nhs.uk/Default.aspx?alias=www. improvement.nhs.uk/qipp. Accessed Apr 2013.

12. National Institute for Health and Clinical Excellence (NICE). Kidney disease: peritoneal dialysis. Costing report. Implementing NICE guidance. July 2011. Available from: www.nice.org.uk/ nicemedia/live/13524/55549/55549.pdf. Accessed Nov 2013.

13. HM Treasury. The green book. Appraisal and evaluation in central government; 2011.

14. Briggs A, Sculpher M. An introduction to Markov modelling for economic evaluation. Pharmacoeconomics. 1998;13(4):397-409.

15. Kirby L, Vale L. Dialysis for end-stage renal disease. Determining a cost-effective approach. Int $\mathbf{J}$ Technol Assess Health Care. 2001;17(2):181-9.

16. NHS purchasing and supply agency. Economic Report Home haemodialysis. CEP10063; 2010.

17. European Renal Association (ERA) and European Dialysis and Transplant Association (EDTA). ERA-EDTA Registry Annual Report 2009. Available from http://www.era-edta-reg.org/files/ annualreports/pdf/AnnRep2009.pdf. Accessed Mar 2013.

18. US Renal Data System. USRDS 2013 Annual Data Report: atlas of chronic kidney disease and end-stage renal disease in the United States. Incidence, prevalence, patient characteristics and treatment modalities. Available from: http://www.usrds.org/2013/ pdf/v2_ch1_13.pdf. Accessed Dec 2013.

19. European Renal Association (ERA) and European Dialysis and Transplant Association (EDTA). ERA-EDTA Registry Annual Report 2011. Available from: http://www.era-edta-reg.org/files/ annualreports/pdf/AnnRep2011.pdf. Accessed Nov 2013.

20. R Core Team. R: A language and environment for statistical computing. R Foundation for Statistical Computing, Vienna; 2012.

21. Chiu YW, Jiwakanon S, Lukowsky L, Duong U, Kalantar-Zadeh $\mathrm{K}$, Mehrotra R. An update on the comparisons of mortality outcomes of hemodialysis and peritoneal dialysis patients. Semin Nephrol. 2011;31(2):152-8.

22. NHS Blood and Transplant. Organ Donation and Transplantation: Activity Report 2012/2013. Available from: http://www. organdonation.nhs.uk/statistics/transplant_activity_report/current_ activity_reports/ukt/activity_report_2012_13.pdf. Accessed Jan 2014.

23. Brown EA, Johansson L, Farrington K, Gallagher H, Sensky T, Gordon F, et al. Broadening options for long-term dialysis in the elderly (BOLDE): differences in quality of life on peritoneal dialysis compared to haemodialysis for older patients. Nephrol Dial Transplant. 2010;25(11):3755-63.

24. Rubin HR, Fink NE, Plantinga LC, Sadler JH, Kliger AS, Powe NR. Patient ratings of dialysis care with peritoneal dialysis vs hemodialysis. JAMA. 2004;291(6):697-703.

25. Goodlad C, Brown E. The role of peritoneal dialysis in modern renal replacement therapy. Postgrad Med J. 1056;2013(89): 584-90.

26. McLaughlin K, Manns B, Mortis G, Hons R, Taub K. Why patients with ESRD do not select self-care dialysis as a treatment option. Am J Kidney Dis. 2003;41(2):380-5.

27. Juergensen E, Wuerth D, Finkelstein SH, Juergensen PH, Bekui A, Finkelstein FO. Hemodialysis and peritoneal dialysis: patients' assessment of their satisfaction with therapy and the impact of the therapy on their lives. Clin J Am Soc Nephrol. 2006;1(6):1191-6.

28. Liem YS, Bosch JL, Hunink MG. Preference-based quality of life of patients on renal replacement therapy: a systematic review and meta-analysis. Value Health. 2008;11(4):733-41. 
29. de Wit GA, Ramsteijn PG, de Charro FT. Economic evaluation of end stage renal disease treatment. Health Policy. 1998;44(3): $215-32$.

30. Lafrance JP, Rahme E, Iqbal S, Elftouh N, Vallee M, Laurin LP, et al. Association of dialysis modality with risk for infectionrelated hospitalization: a propensity score-matched cohort analysis. Clin J Am Soc Nephrol. 2012;7(10):1598-605.

31. Chertow GM, Levin NW, Beck GJ, Depner TA, Eggers PW, Gassman JJ, et al. In-center hemodialysis six times per week versus three times per week. N Engl J Med. 2010;363(24): 2287-300.

32. Arora P, Kausz AT, Obrador GT, Ruthazer R, Khan S, Jenuleson CS, et al. Hospital utilization among chronic dialysis patients. J Am Soc Nephrol. 2000;11(4):740-6.

33. Xue H, Ix JH, Wang W, Brunelli SM, Lazarus M, Hakim R, et al. Hemodialysis access usage patterns in the incident dialysis year and associated catheter-related complications. Am J Kidney Dis. 2013;61(1):123-30.

34. Department of Health. Payment by results 2013-2014. Available from: https://www.gov.uk/government/collections/payment-byresults-2013-14. Accessed Jan 2014.

35. British Medical Association. British National Formulary (BNF), No. 67. London: British Medical Association and the Royal Pharmaceutical Society of Great Britain; 2014.

36. Rao A, Gilg J, Williams A. UK Renal Registry 15th Annual Report (December 2012): Chapter 6: Haemoglobin, Ferritin and Erythropoietin amongst UK Adult Dialysis Patients in 2011: national and centre-specific analyses. Available from: http:// www.renalreg.com/Report-Area/Report\%202012/Chapter_6.pdf Accessed Jan 2014.

37. Department of Health. NHS Reference costs 2011-2012. Available from: http://www.dh.gov.uk/health/2012/11/2011-12-referencecosts/ Accessed Jan 2014.

38. Department for Work and Pensions. Z1-Recovery of benefits and or lump sum payments and NHS charges: Procedures for liaison with the Compensation Recovery Unit; 2013.

39. Department of Health. NHS Reference costs 2009-2010. Available from: http://www.dh.gov.uk/en/Publicationsandstatistics/ Publications/PublicationsPolicyAndGuidance/DH_123459. Accessed Jan 2014.

40. The NHS Information Centre. National Kidney Care Audit. Patient Transport Survey 2010; 2011.

41. NHS Kidney Care. Developing robust reference costs for kidney transplantation in adults-Update; 2011.

42. Department of Health. NHS Reference costs 2012-2013. Available from: https://www.gov.uk/government/publications/nhsreference-costs-2012-to-2013. Accessed Feb 2014.

43. Gonzalez-Perez JG, Vale L, Stearns SC, Wordsworth S. Hemodialysis for end-stage renal disease: a cost-effectiveness analysis of treatment-options. Int J Technol Assess Health Care. 2005;21(1):32-9.

44. Mowatt G, Vale L, Perez J, Wyness L, Fraser C, MacLeod A et al. Systematic review of the effectiveness and cost-effectiveness, and economic evaluation, of home versus hospital or satellite unit haemodialysis for people with end-stage renal failure. Health Technology Assessment 2003. Available from: http:// www.journalslibrary.nihr.ac.uk/hta/volume-7/issue-2. Accessed 16 Sept 2013.

45. Haller M, Gutjahr G, Kramar R, Harnoncourt F, Oberbauer R. Cost-effectiveness analysis of renal replacement therapy in Austria. Nephrol Dial Transplant. 2011;26(9):2988-95.

46. McFarlane PA, Bayoumi AM, Pierratos A, Redelmeier DA. The quality of life and cost utility of home nocturnal and conventional in-center hemodialysis. Kidney Int. 2003;64(3):1004-11.
47. National Institute for Health and Clinical Excellence (NICE). Cost effectiveness of peritoneal dialysis provision. Available from http://www.nice.org.uk/nicemedia/live/12347/52540/52540. pdf. Accessed Apr 2013.

48. Lukowsky LR, Mehrotra R, Kheifets L, Arah OA, Nissenson AR, Kalantar-Zadeh K. Comparing mortality of peritoneal and hemodialysis patients in the first 2 years of dialysis therapy: a marginal structural model analysis. Clin J Am Soc Nephrol. 2013;8(4):619-28.

49. Sinnakirouchenan R, Holley JL. Peritoneal dialysis versus hemodialysis: risks, benefits, and access issues. Adv Chronic Kidney Dis. 2011;18(6):428-32.

50. Villa G, Fernandez-Ortiz L, Cuervo J, Rebollo P, Selgas R, Gonzalez T, et al. Cost-effectiveness analysis of the Spanish renal replacement therapy program. Perit Dial Int. 2012;32(2):192-9.

51. Howard K, Salkeld G, White S, McDonald S, Chadban S, Craig JC, et al. The cost-effectiveness of increasing kidney transplantation and home-based dialysis. Nephrology (Carlton). 2009; 14(1):123-32.

52. Neil N, Walker DR, Sesso R, Blackburn JC, Tschosik EA, Sciaraffia V, et al. Gaining efficiencies: resources and demand for dialysis around the globe. Value Health. 2009;12(1):73-9.

53. Department of Health. Making the NHS more efficient and less bureaucratic (March 2013). Available from https://www.gov. uk/government/policies/making-the-nhs-more-efficient-and-lessbureaucratic. Accessed Apr 2013.

54. Johnson DW, Dent H, Hawley CM, McDonald SP, Rosman JB, Brown FG, et al. Associations of dialysis modality and infectious mortality in incident dialysis patients in Australia and New Zealand. Am J Kidney Dis. 2009;53(2):290-7.

55. McFarlane PA, Bayoumi AM, Pierratos A, Redelmeier DA. The impact of home nocturnal hemodialysis on end-stage renal disease therapies: a decision analysis. Kidney Int. 2006;69(5): 798-805.

56. Rocco MV, Lockridge RS Jr, Beck GJ, Eggers PW, Gassman JJ, Greene T, et al. The effects of frequent nocturnal home hemodialysis: the frequent hemodialysis network nocturnal trial. Kidney Int. 2011;80(10):1080-91.

57. Gilg J, Castledine C, Fogarty D, Feest T. UK Renal Registry 13th Annual Report (December 2010): Chapter 1: UK RRT incidence in 2009: national and centre-specific analyses. Nephron Clin Pract. 2011;119(Suppl 2):c1-25.

58. Steenkamp R, Castledine C, Feest T, Fogarty D. UK Renal Registry 13th Annual Report (December 2010): Chapter 2: UK RRT prevalence in 2009: national and centre-specific analyses. Nephron Clin Pract. 2011;119(Suppl 2):c27-52.

59. NHS blood and transplant. activity report 2012/2013. Transplant Activity in the UK http://www.organdonation.nhs.uk/statistics/ transplant_activity_report/current_activity_reports/ukt/activity_ report_2012_13.pdf. Accessed Dec 2013.

60. NHS Kidney Care. Frequently asked questions. payment by results (PbR)-Renal dialysis. Feb 2011. Available from http://webarchive.nationalarchives.gov.uk/20130504185629/http:// kidneycare.nhs.uk/resources/?dispFolder=503\#. Accessed Jan 2014.

61. Rao A, Gilg J, Williams A. UK Renal Registry 16th Annual Report: chapter 10 haemoglobin, ferritin and erythropoietin amongst UK adult dialysis patients in 2012: National and Centrespecific Analyses. Available from: http://www.renalreg.com/ Report-Area/Report\%202013/10-Chap-10.pdf. Accessed May 2014.

62. Department of Health. NHS Reference costs 2010-2011. Available from: https://www.gov.uk/government/publications/201011-reference-costs-publication. Accessed Feb 2014. 